\title{
Carbon emission assessment of the life cycle of a small town sewage treatment plant
}

\author{
Lin Lin \\ Jilin City Radio and Television University, 132000Jilin, China
}

\begin{abstract}
The rise of greenhouse gas (GHG) concentration has caused global warming to become a consensus in human society. Carbon emissions from sewage treatment plants are one of the main sources of emissions. Among them, carbon emissions from small town sewage treatment plants cannot be ignored. Based on the life cycle (LCA) evaluation theory, the assessment scope of life cycle carbon emissions of small town sewage treatment plants is defined, and a corresponding evaluation system is constructed. According to the system, the carbon emissions of a small town sewage treatment plant in Jilin are evaluated. Based on the assessment results, the ways to reduce carbon emissions from small town sewage treatment plantswerediscussedto provide a reference for their emission reduction.
\end{abstract}

\section{Foreword}

The cause of global warming is generally believed to be excessive emissions of greenhouse gases such as $\mathrm{CO}_{2}$, $\mathrm{CH}_{4}$ and $\mathrm{N}_{2} \mathrm{O}$ into the atmosphere during human activities, which has prompted international agreements and conferences on greenhouse gas reductions, including the Kyoto Protocol. Sewage treatment plant directly discharges $\mathrm{CO}_{2}$ and $\mathrm{CH}_{4}$ during operation. Greenhouse gases such as $\mathrm{N}_{2} \mathrm{O}$, energy and resource consumption also indirectly generate greenhouse gases. Therefore, sewage treatment plants are considered to be one of the main sources of carbon emissions [1].

The "12th Five-Year Plan for the Construction of Urban Sewage Treatment and Recycling Facilities" requires that the sewage treatment rate of the towns reached $30 \%$ by 2015 , which has been basically completed. The "13th Five-Year Plan for Urban Sewage Treatment and Recycling Facilities Construction" proposes that by the end of 2020, urban sewage treatment facilities will be fully covered, and the towns will reach $70 \%$. With the large-scale construction of small town sewage treatment plants, huge carbon emissions will be generated during construction, operation and demolition due to energy consumption, material consumption, direct discharge of operations and disposal of solid waste.

Compared with urban sewage treatment plants, small town sewage treatment plants have the following characteristics: small towns are small in size, low in population density, small in population, low in industrial development, small in sewage and water; residents are concentrated in water, early in the evening the water consumption is large, the water consumption is small at other times, and even the flow may occur at night. Therefore, the amount of sewage water and water quality fluctuate greatly; the complex terrain, scattered residents and weak environmental awareness make the drainage network system imperfect, which increases the amount of sewage treatment water in small towns and the concentration of organic matter in sewage are reduced; the economy is underdeveloped, the funds for sewage treatment are insufficient, the operation management technology is weak, and the professional sewage treatment cannot be guaranteed to operate normally. These characteristics make it difficult to directly use the treatment process of large-scale sewage treatment plants in small town sewage treatment. Therefore, it is necessary to evaluate the carbon emissions of small town sewage treatment plants.

Based on the life cycle assessment theory, this paper analyzes the carbon emissions that may occur during the construction, operation and demolition of small town urban sewage treatment plants, in order to objectively understand the carbon emissions of small town sewage treatment plants and provide reference for the ways to reduce carbon emissions of small town sewage treatment plants.

\section{Life cycle carbon emission assessment system for small town sewage treatment plants}

\subsection{Assessment range}

Assessing the carbon emissions from the life cycle of a small town sewage treatment plant can consider the carbon emissions of the small town sewage treatment plant life cycle as a system to assess the total $\mathrm{CO}_{2}$ equivalent of the system due to energy consumption, material consumption and treatment process to the 
environment. The life cycle of a small town sewage treatment plant refers to the whole process from "cradle" to "grave", including raw material mining, civil engineering materials, equipment processing and manufacturing, civil construction, equipment installation, operation and maintenance of sewage treatment plants and demolition. Evaluating plant-wide life cycle carbon emissions can assess carbon emissions in the construction, operation, and demolition phases, as shown in Figure 1.

During the construction phase, civil construction and equipment installation consume a lot of building materials, building materials in the production process due to energy consumption and various materials produce a large amount of carbon emissions, construction process and equipment, manufacturing and manufacturing the process produces carbon emissions due to mechanical energy consumption. Carbon emissions during the operation phase are composed of direct emissions of greenhouse gases such as sewage, sludge treatment processes $\mathrm{CO}_{2}, \mathrm{CH}_{4}$ and $\mathrm{N}_{2} \mathrm{O}$, as well as indirect emissions of energy and pharmaceutical consumption.It should be pointed out that this stage does not include the energy consumption and carbon emissions corresponding to tail water discharge or recovery, sludge transfer and disposal. Carbon emissions during the demolition phase should be deducted from the recycling of some building materials carbon emissions.

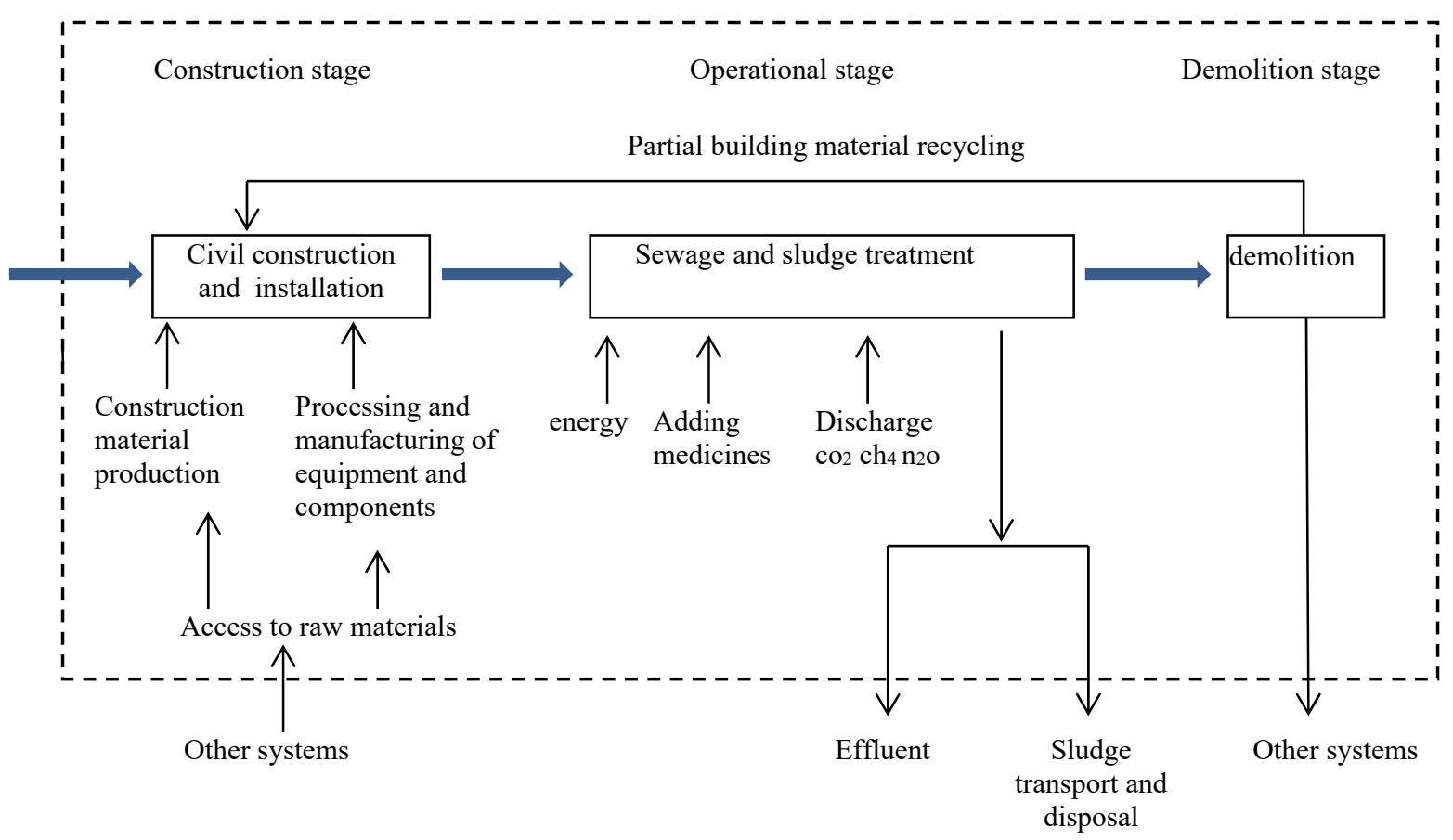

Fig. 1 Assessment system boundary of life-cycle carbon emission for sewage treatment plants in small towns

\section{2 Evaluation indicators}

The treatment scale, treatment water quality, treatment level and treatment process of small town sewage treatment plants are different,there is a large difference in material and mechanical usage and energy consumption during the construction process, the impact on carbon emissions during the operational phase is also significant.Eliminate the impact of scale of sewage treatment,select the carbon emissions corresponding to each cubic meter of sewage as the evaluation index, this is also the main selection evaluation index for the study of carbon emissions from urban sewage treatment in China.However, there are certain limitations in the treatment of carbon emissions per cubic metre of sewage as the sole evaluation criteria,large differences in water quality can also result in different carbon emissions from sewage treated with the same amount of water[2].In order to eliminate the impact of different sewage quality and treatment levels, the carbon emissions corresponding to the removal of BOD per kilogram were selected as evaluation indicators.

Therefore, in order to establish a horizontally comparable evaluation, the evaluation results is made consistent and comparable,this study selected two evaluation indicators:the carbon emissions per cubic metre of sewage are treated and the carbon emissions per kilogram of BOD are removed.

\section{Small town sewage treatment plant carbon emission assessment method}

For carbon emissions, it is generally measured in terms of the amount of $\mathrm{CO}_{2}$ produced, other greenhouse gases 
other than $\mathrm{CO}_{2}$, such as $\mathrm{CH}_{4}, \mathrm{~N}_{2} \mathrm{O}$, etc, it can be converted to carbon equivalent based on global warming potential (GWP), the potential value of $\mathrm{CO}_{2}$ is 1 , and the potential values of $\mathrm{CH}_{4}$ and $\mathrm{N}_{2} \mathrm{O}$ are 23 and 296[3], respectively,the carbon emissions of the small town sewage treatment plant life cycle are equal to the three stages of construction, operation and demolition of various greenhouse gas emissions, the sum of the amount of multiplication with its GWP.

\section{1 Construction stage}

Small town sewage treatment plants consume a large amount of various building materials and use various machinery during the construction process.But because of the variety of materials used,it is difficult to evaluate one by one,in this paper, all materials are sorted according to energy consumption and cost,materials with a cumulative amount of more than $80 \%$ of the total materials are included in the evaluation, other carbon emissions that are not directly calculated are $5 \%$ of the calculated carbon emissions. The calculation formula for carbon emissions during the construction phase is as follows:

$$
\mathrm{Mco}_{2 \cdot \mathrm{W}}=1.05 \Sigma \mathrm{W}_{i} \times \mathrm{EFCO}_{2 \cdot \mathrm{Wi}}
$$

In formula (1): $\mathrm{Mco}_{2 \cdot \mathrm{W}}-\mathrm{CO}_{2}$ during construction emission quantity, unit: $\mathrm{kg}$;

$\mathrm{Wi}$-Construction material i consumption during construction, in: $\mathrm{Kg}$;

$\mathrm{CO}_{2}$ consumed by $\mathrm{EFcO}_{2 \cdot \mathrm{Wi}}-\mathrm{i}$ materials emission factor, unit $\mathrm{kgCO}_{2} / \mathrm{kg}$. According to existing research, the main $\mathrm{CO}_{2}$ during the construction phase

The emission factors are shown in Table $1[4 \sim 7]$.

Table. $1 \mathrm{CO}_{2}$ emission factors during construction stage

$\left(\mathrm{kgCO}_{2} / \mathrm{kg}\right)$

\begin{tabular}{ccccccccc}
\hline cement & \multicolumn{3}{c}{ Steel } & & Energy & & plastic \\
\hline cement & Large steel & $\begin{array}{c}\text { Small and } \\
\text { medium steel }\end{array}$ & $\begin{array}{c}\text { Hot } \\
\text { rolled } \\
\text { strip }\end{array}$ & $\begin{array}{c}\text { Cold } \\
\text { rolled } \\
\text { strip }\end{array}$ & gasoline & diesel & PE & UPVC \\
0.716 & 2.800 & 2.320 & 2.430 & 2.940 & 2.031 & 2.171 & 0.603 & 4.700 \\
\hline
\end{tabular}

Note: $\mathrm{CO}_{2}$ of cement the emission factor is based on the cement clinker ratio of construction of 0.75 .

\section{2 operation stage}

Carbon emissions from the operation phase of small town sewage treatment plants include direct emissions and indirect emissions. Sewage collection, sewage treatment and sludge treatment process directly discharge greenhouse gases such as $\mathrm{CO}_{2}, \mathrm{CH}_{4}$ and $\mathrm{N}_{2} \mathrm{O}$ into the environment. In the United Nations Intergovernmental Panel on Climate Change (IPCC) Recommendation Methodology Guide, directly emitted $\mathrm{CO}_{2}$ is bio-based and therefore not included in total carbon emissions [8], this article also does not consider, therefore, direct emissions are mainly derived from the emissions of biological treatment processes $\mathrm{CH}_{4}$ and $\mathrm{N}_{2} \mathrm{O}$; indirect emissions include carbon emissions from power consumption and drug consumption in each process unit.

\subsubsection{Direct emissions}

The calculation of direct emissions refers to the 2005 China Greenhouse Gas Inventory Study and the 2006 National Greenhouse Gas Inventories Guide[8] published by the IPCC, the amount of $\mathrm{CH}_{4}$ produced is calculatedas follows:

$$
\mathrm{M}_{\mathrm{CH}_{4}}=\left(\mathrm{TOW} \times \mathrm{EF}_{\mathrm{CH}_{4}}\right)-\mathrm{R}_{0}
$$

In formula (2): $\mathrm{M}_{\mathrm{CH}_{4}}-\mathrm{CH}_{4}$ during biological treatment emission quantity, unit: $\mathrm{kg}$;

TOW-calculate the organic matter content of the annual sewage, unit: kg;
$\mathrm{EF}_{\mathrm{CH}_{4}}-\mathrm{CH}_{4}$ emission factors, refer to Cai Bofeng et al [9] study the methane emission factor of the aerobic during the operation of the sewage treatment plant,the treatment process.

$\mathrm{R}_{0}$ - calculate the annual recovered $\mathrm{CH}_{4}$ quantity, unit: $\mathrm{kg}$, if dirty mud digestion facility is not running, $\mathrm{R}_{0}$ take the default value of 0 .

$$
M_{\mathrm{N}_{2} \mathrm{O}}=T N \times E F_{\mathrm{N}_{2} \mathrm{O}}
$$

$\mathrm{M}_{\mathrm{N}_{2} \mathrm{O}}$ in formula (3) $-\mathrm{N}_{2} \mathrm{O}$ emissions during biological treatment quantity, unit: $\mathrm{kg}$;

$\mathrm{TN}$ - calculate the total amount of nitrogen removed from the annual sewage, in units of $\mathrm{kg}$;

$\mathrm{EF}_{\mathrm{N}_{2} \mathrm{O}}-\mathrm{N}_{2} \mathrm{O}$ emission factor, refer to Kimochi $\mathrm{Y}$ et al. [10] the $\mathrm{N}_{2} \mathrm{O}$ emission factor of the intermittent aerated activated sludge process in the study.

\section{2. 2 Indirect emissions}

lifting pump unit, the aeration blast unit, the drug convey unit, and the sludge unit will consume a lot of energy,the production of these energy sources will have carbon emissions, the calculation formula is as follows:

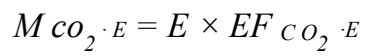

$\mathrm{Mco}_{2} \cdot \mathrm{E}$ - energy consumption in the formula indirectly emits $\mathrm{CO}_{2}$ the amount, unit: $\mathrm{kg}$;

$\mathrm{E}$ - power consumption, unit: $\mathrm{kW} \cdot \mathrm{h}$;

$\mathrm{EF}_{\mathrm{CO}_{2}} \cdot \mathrm{E}-\mathrm{CO}_{2}$ for power consumption emission factor, unit: $\mathrm{Kg} \mathrm{CO}_{2} / \mathrm{kW} \cdot \mathrm{h}$, according to the $2015 \mathrm{China}$ Regional Grid Reference Line Emission Factor are 
determined.

treatment will use a large amount of chemicals, such as stone. Ash, methanol, coagulant and disinfectant for better sludge pressure reduce the effect, use a large amount of flocculant, coagulant and so on. Drug consumption carbon row put the calculation formula as follows:

$$
\mathrm{Mco}_{2} \cdot Y=\Sigma Y_{i} \times \mathrm{EFCO}_{2} \cdot \mathrm{Y}_{i}
$$

$\mathrm{McO}_{2} \cdot \mathrm{Y}$ in the formula (5) -indirect $\mathrm{CO}_{2}$ emissions, single bit: kg;

$\mathrm{Yi}$ - pharmaceutical i consumption, unit: $\mathrm{kg}$;

$\mathrm{EFCO}_{2} \cdot \mathrm{Yi}_{\mathrm{K}}-\mathrm{i} \mathrm{CO}_{2}$ consumed by the agent emission factor,unit: $\mathrm{KgCO}_{2} / \mathrm{kg}$, according to statistics, $\mathrm{EFCO}_{2 \text { •coagulant }}$ is $25 \mathrm{kgCO}_{2} / \mathrm{kg}$ coagulant.

\section{3 Demolition phase}

The carbon emissions during the demolition phase mainly include the carbon emissions generated by the demolition process and waste transportation and waste disposal, however, some materials are recycled to reduce raw material production, therefore, the carbon emissions in the demolition phase should be deducted from the carbon emissions corresponding to the recycled materials. Among them, the carbon emissions from the demolition process and waste transportation can be assessed by the
In order to meet the standard discharge, sewage energy consumed during the dismantling and transportation of the waste.

\section{4 case study}

\subsection{Overview of small town sewage treatment plants}

According to the characteristics of the small town sewage treatment plant, when selecting a process suitable for treating sewage in small towns, CASS process has a high degree of applicability [ $11-$ 12]. This paper takes a small town sewage treatment plant with a treatment scale of $2000 \mathrm{~m}^{3} / \mathrm{d}$ in Jilin as an example, the treatment process is "pretreatment + CASS + coagulation and phosphorus removal + filtration disinfection", after treatment, the effluent water quality meets the Grade A standard of the Pollutant Discharge Standard for Urban Sewage Treatment Plants (GB18918 - 2002), the process flow is shown in figure 2. The small town sewage treatment plant has a structural design period of 50 years.

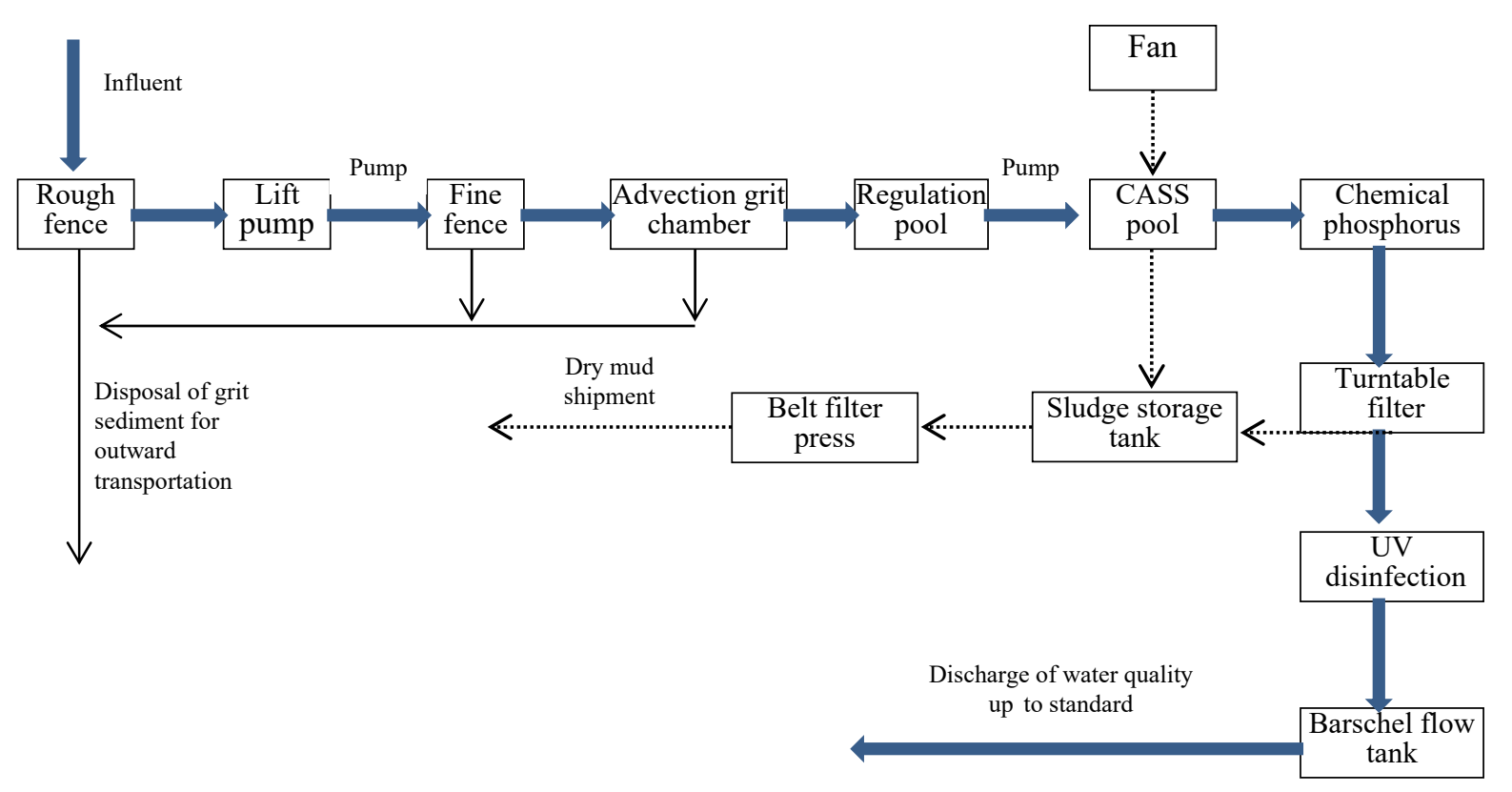

Fig. 2 The process flow diagram of a typical small town sewage treatment plant

Due to the lack of basic data for the demolition phase, this case only calculates the carbon emissions during the construction phase and the operational phase. (1) The data for the construction phase comes from the construction plan, the bill of quantities and the construction budget. The main materials are shown in Table 2.

Table. 2 Materials quantity and energy consumption in construction stage

\begin{tabular}{rccccccccc}
\hline $\begin{array}{r}\text { Construction } \\
\text { materials }\end{array}$ & cement & $\begin{array}{c}\text { Reinforce } \\
\text { ment }\end{array}$ & $\begin{array}{c}\text { Steel plate, } \\
\text { Section steel }\end{array}$ & $\begin{array}{c}\text { Steel } \\
\text { Pipe }\end{array}$ & $\begin{array}{c}\text { Other } \\
\text { steel }\end{array}$ & PE tube & $\begin{array}{c}\text { UPVC } \\
\text { pipe }\end{array}$ & gasoline & Diesel \\
\hline consumption & 668.131 & 169.709 & 20.556 & 54.149 & 0.418 & 9.504 & 0.323 & 3.352 & 21.842 \\
\hline
\end{tabular}


(2) This study collected basic data such as water quality, sewage treatment capacity, electricity consumption, and chemical use of the sewage treatment plant in 2016.In 2016, the total amount of treated sewage was about 763200 tons, and the water quality of the inlet and outlet was taken as the 2016 average. See Table 3 for details.

Table. 3 Water quality of the small town sewage treatment plant

\begin{tabular}{ccccc}
\hline index & Treatment volume $(\mathrm{t} / \mathrm{a})$ & $\mathrm{BOD}_{5}(\mathrm{mg} / \mathrm{L})$ & $\mathrm{COD}_{\mathrm{cr}}(\mathrm{mg} / \mathrm{L})$ & $\mathrm{TN}(\mathrm{mg} / \mathrm{L})$ \\
\hline Influent water quality & \multirow{2}{*}{763200} & 121 & 253 & 34 \\
Effluent water quality & & 8 & 42 & 13 \\
\hline
\end{tabular}

The annual electricity consumption of the small town sewage treatment plant is $195379.2 \mathrm{~kW} \cdot \mathrm{h}$, the power consumption per sewage is $0.256 \mathrm{~kW} \cdot \mathrm{h}$, the main agents are PAM, PAC coagulant. The annual usage is $0.23 \mathrm{t}$ and $10.62 \mathrm{t}$.

\section{2 Carbon emission assessment and analysis}

Table 4. Life - cycle carbon emission of the small town sewage treatment plant

\begin{tabular}{|c|c|c|c|c|c|}
\hline & \multirow{2}{*}{ Construction phase } & \multicolumn{3}{|c|}{ Operational stage } & \multirow{2}{*}{ total } \\
\hline & & Direct emissions & Indirect emissions & total & \\
\hline Carbon emission & $1228.47 \mathrm{t}$ & $16.95 \mathrm{t} / \mathrm{a}$ & $457.15 \mathrm{t} / \mathrm{a}$ & $474.1 \mathrm{t} / \mathrm{a}$ & \\
\hline $\begin{array}{c}\text { Evaluation index } \\
\left(\mathrm{kg} / \mathrm{m}^{3}\right)\end{array}$ & 0.03 & 0.02 & 0.60 & 0.62 & 0.65 \\
\hline $\begin{array}{l}\text { Evaluation index } \\
\text { (kg / kg BOD) }\end{array}$ & 0.28 & 0.20 & 5.30 & 5.5 & 5.78 \\
\hline
\end{tabular}

As can be seen from Table 4 , the small town sewage treatment plant has a large carbon emission during the construction phase, reaching 1228 . 47t, however, the sewage treatment plant has a structural life of 50 years, amortize carbon emissions from its construction phase to less per cubic metre of sewage or remove carbon emissions per kilogram of BOD, only $0.03 \mathrm{~kg} / \mathrm{m}^{3}, 0.28$ $\mathrm{kg} / \mathrm{kg}$ BOD. The sewage treatment plant's carbon emissions during the life cycle is as high as 46 272.97 t,carbon emissions during the construction phase account for approximately $5 \%$ of total life cycle carbon emissions, less contribution to total carbon emissions from the life cycle of small town sewage treatment plants.

Among them, the carbon emission of steel is $630.12 \mathrm{t}$, accounted for $51.29 \%$ of the total carbon emissions during the construction phase, it can be seen that reducing the carbon emissions of steel is an important way to achieve low carbonization during the construction phase. Steel is a high carbon emission building material, but its recovery rate is also high. Considering that it is difficult to fully recycle steel in reinforced concrete, the recovery rate is $40 \%$, section steel, steel pipe and other steels have higher recovery rates, up to $90 \%$, the carbon emissions of recycled steel are based on $35 \%$ of the original steel carbon emissions. Consider recycling, the carbon emission of the sewage treatment plant is 395.53 t, the total carbon emissions during the construction phase were reduced to 993.88 t,nearly $20 \%$ of total carbon emissions during the
According to 3.1 , the carbon emissions of the sewage treatment plant during the construction phase and the operation phase are calculated separately. The results are shown in Table 4. construction phase have been reduced.

Carbon emissions during the operational phase are concentrated on indirect emissions, the direct conversion of $\mathrm{CH}_{4}$ and $\mathrm{N}_{2} \mathrm{O}$ emissions is only $14.82 \mathrm{t} / \mathrm{a}$ and $2.13 \mathrm{t} / \mathrm{a}$ respectively, the carbon emissions from energy consumption are $185.90 \mathrm{t} / \mathrm{a}$, the drug consumption carbon emission is $271.25 \mathrm{t} / \mathrm{a}$, indirect emissions account for approximately $95 \%$ of total carbon emissions during the operational phase. The treatment of small town sewage treatment plants is relatively small, the energy consumption per unit of water is greater than that of urban sewage treatment plants. This study uses a chemical phosphorus removal process, adding a large amount of PAC during operation to achieve phosphorus removal, increasing the carbon consumption of the drug, the sewage treatment plant has a relatively large amount of drug consumption, it accounted for $57.21 \%$ of the total carbon emissions during the operation phase. Taking the carbon emissions corresponding to each cubic meter of sewage as an evaluation index, the carbon emission of the sewage treatment plant during the operation phase is $0.65 \mathrm{~kg} / \mathrm{m}^{3}$, slightly lower than the carbon emissions of domestic urban sewage treatment plants [2];taking the carbon emissions corresponding to the removal of BOD per $\mathrm{kg}$ as an evaluation index, the carbon emission of the sewage treatment plant during the operation phase is $5.78 \mathrm{~kg} / \mathrm{kg}$ BOD, higher than the similar study of urban sewage treatment plants [2], this is caused by the low BOD of the water entering the small town sewage treatment plant. 
To achieve the emission reduction targets of small carbon emissions during the construction phase and operation phase, it is especially important to reduce the carbon emissions during the operational phase. The ways to reduce carbon emissions during the construction phase are: (1) clean production and reduce carbon emissions during building materials production;(2)sewage treatment plants reduce the use of building materials with more carbon emissions in the production process; (3)improve the efficiency of mechanical use and reduce energy consumption such as diesel; (4) recycling resources to recover building materials as much as possible to reduce carbon emissions. The ways to reduce carbon emissions during the operational phase are:(1) biogas recovery. If $\mathrm{CH}_{4}$ is burned, it can be converted into $\mathrm{CO}_{2}$ with low global warming potential, at the same time, the energy produced by combustion can be used as an energy supply; (2)optimize equipment such as lifting pumps and blowers, reduce energy consumption; (3)do a good job of saving water at the source, sewage reuse to reduce the treatment load of the sewage treatment plant, indirectly reduce carbon emissions; (4) reasonable allocation of drug consumption, etc, enable sewage treatment plants to operate at low carbon.

\section{Conclusion}

According to the principle of life cycle assessment, defining the scope of assessment of life cycle carbon emissions from small town sewage treatment plants, the carbon emissions of the construction, operation and demolition phases of the small town sewage treatment plant were analyzed, established a life cycle carbon emission assessment system for small town sewage treatment plants, and carried out a case study.

The case study shows that, large carbon emissions during the construction phase, but measured by the life cycle, its carbon emissions account for only $5 \%$ of total carbon emissions. Among them, the carbon emissions of steel accounted for $51.29 \%$ of the total carbon emissions during the construction phase, through recycling, carbon emissions can be reduced by $20 \%$ during the construction phase, significantly reduce carbon emissions at this stage. Reducing carbon emissions during the construction phase can also be achieved through cleaner production, reduced use of high carbon emissions building materials and improved mechanical performance. Carbon emissions in the operational phase are the main part of the total carbon emissions of the town sewage treatment plants, it is necessary to reduce plant, its carbon emissions are concentrated in indirect carbon emissions, indirect emissions, energy consumption and drug consumption accounted for $39.21 \%$ and $57.21 \%$ of the carbon emissions in the operational phase, reduce energy consumption by optimizing mechanical equipment, reasonable allocation of drug consumption and other aspects of indirect carbon emissions with less operating phase. This study calculate carbon emissions at various stages of the life cycle of a small town sewage treatment plant, master the main factors of carbon emissions, find reasonable low-carbon measures, provide a scientific basis for its emission reduction.

\section{References}

1. C. Sweetapple, G. Fu, D. Butler. Water Res. J. 62, 249-259(2014)

2. T. Xie, C. Wang. Qhdxxb.J. 52, 473-477(2012)

3. P. Falkowski, R. J. Scholes, E. Boyle, et al. Science.J. 290, 291-296(2000)

4. L. Shen, J. Zhao, L. Wang, et al. Kxtb.J. 61, 29262938(2016)

5. Y. Gao. Carbon Footprint Evaluation Method and Empirical Study of Building Products in Physical and Chemical Stage .D. (Tsinghua University, Beijing,2012)

6. M. Li, Z. Wang, D. Sun. Hjkxyjs. J. 32, 191-195 (2009)

7. J. Li, Y. Liu. Gcglxb. J. 29, 12-16(2015)

8. IPCC. 2006 IPCC GuidelinesFor National Greenhouse Gas Inventories[M/OL]. (iGES, Japan,2006)

9. B. Cai, Q. Gao, Z. Li, et al. Zgrk·zyyhj.J. 25, 118124(2015)

10. Y. Kimochi, Y. Inamori, M. Mizuochi, et al. J.Ferment.Bioeng.J.86, 202-206(1998)

11. W. Ma. Analysis and evaluation of applicable technical processes for sewage treatment in small towns .D.(Xi'an University of Architecture and Technology, Xi'an,2013)

12. Y. Qian. Optimization study on waste water treatment process selection in small and mediumsized cities.D. (Southwest Jiaotong University, Chengdu, 2017) 